\title{
Enquête
}

Archives de la revue Enquête

$8 \mid 1993$

Varia

\section{Actions sociales et relativisme culturel}

Les bibliothèques de $\mathrm{CE}$ et la lecture des livres

\section{Philippe Gaboriau}

\section{(2) OpenEdition}

Journals

\section{Édition électronique}

URL : http://journals.openedition.org/enquete/176

DOI : 10.4000/enquete. 176

ISSN : 1953-809X

Éditeur :

Cercom, Éditions Parenthèses

Édition imprimée

Date de publication : 2 septembre 1993

Pagination : 113-120

Référence électronique

Philippe Gaboriau, "Actions sociales et relativisme culturel », Enquête [En ligne], 8 | 1993, mis en ligne le 09 juillet 2013, consulté le 02 mai 2019. URL : http://journals.openedition.org/enquete/176 ; DOI :

10.4000/enquete. 176

Ce document a été généré automatiquement le 2 mai 2019. 


\section{Actions sociales et relativisme culturel}

Les bibliothèques de CE et la lecture des livres*

\section{Philippe Gaboriau}

On peut prendre le parti - presque tous le font - de tenir pour incontestable ce que nos yeux voient. Mais voient-ils? Ce qui est vu passe, au moment que la pensée s'en saisit, par une grille assimilatrice. Ce que la pensée reçoit n'est qu'une interprétation, une traduction codée. On se trompe quand on identifie la réalité à la vision que nous croyons avoir des choses. La grille au travers de laquelle elles sont perçues par nous est d'usage si constant que nous sommes portés à l'oublier. À tenir pour incontestable ce qu'elle nous représente et pour aberrante la mise en œuvre d'autres codes de figuration et de vision.

JEAN DUBUFFET.

C'est désespérant : tout lire, et ne rien retenir ! Car on ne retient rien. On a beau faire effort : tout échappe. Ça et là, quelques lambeaux demeurent, encore fragiles, comme ces flocons de fumée indiquant qu'un train a passé. JULES RENARD.

\section{Bibliothèque, action sociale et société plurielle}

1 Les bibliothèques (et tout particulièrement les bibliothèques de Comité d'Entreprise) sont, en soi, des carrefours culturels. Des institutions attachées à la diffusion du livre et de la lecture dans les divers milieux sociaux. 
2 Les bibliothèques - les statistiques actuelles le montrent - tendent à correspondre aux attentes et aux pratiques des classes moyennes (Passeron, 1991). En cela, elles ont des résultats très positifs. Les bibliothèques favorisent les pratiques de lecture pour les employé(e)s et les cadres moyens.

3 Par contre, les efforts de démocratisation de la lecture se heurtent à deux réalités sociologiques :

- Les attitudes culturelles des milieux populaires (ouvriers en tête) sont, majoritairement, orientées vers d'autres valeurs de loisirs.

- Lire un livre est une pratique impossible pour de nombreux individus (« c'est trop long à lire »). Pour lire un livre, il est nécessaire, non seulement de savoir lire, mais aussi de savoir lire vite et beaucoup. Cette capacité se répartit de manière inégale selon les milieux sociaux.

\section{Spécificités de l'écrit}

4 L'écrit n'est pourtant pas un outil comme les autres (Passeron, 1991). Il est un multiplicateur de la communication. Un accélérateur de la pensée humaine. Le médium le plus performant pour le stockage des savoirs et savoir-faire. En tant que tel, il est un outil nécessaire pour chaque espace culturel à l'intérieur de notre société.

5 Mais les pratiques de lecture sont liées à la réussite scolaire : les chances de s'adonner à la lecture et d'aimer lire sont en rapport étroit avec le niveau d'étude atteint. Les filières suivies pendant la scolarité (les filières performantes de l'enseignement général s'opposant aux filières de l'enseignement technique) sont aussi influentes.

\section{Cultures et sociétés}

6 Le livre et la lecture se placent au cœur des relations complexes qui s'établissent entre cultures légitimes (cultures lettrées) et autres cultures (cultures souvent dominées) de notre société.

7 L'espace social de la France forme une société plurielle qui possède plusieurs cultures, plusieurs types de modes de vie et de valeurs qui se côtoient, se pénètrent et, souvent, s'opposent. Les différentes strates culturelles de notre société obéissent à plusieurs logiques de pensée.

8 Cet espace pluriculturel est peuplé d'une multitude de quiproquos. Les valeurs de l'autre sont souvent perçues comme de fausses valeurs (de Certeau, 1980).

\section{Bibliothèques de CE et culture ouvrière}

Question : comment démocratiser la lecture?

Réponse possible: Il faut se garder de confondre ce projet avec celui de faire sortir les individus des milieux qui ne lisent pas de leur culture spécifique. Faire sortir les ouvriers, par exemple, de la culture ouvrière. «Le but n'est pas de dé-culturer les pratiquants de cultures non livresques mais de faire entrer le livre dans les cultures où il était jusqu'ici inopérant. » (Passeron, 1991). 


\section{Bibliothèque de $\mathrm{CE}$ et patchwork culturel}

11 La bibliothèque de $\mathrm{CE}$ a, alors, un rôle : permettre l'épanouissement de chaque adulte à l'intérieur de sa propre culture, ses propres valeurs. Permettre à chaque individu de s'auto-construire en permanence. Permettre à chacun les rencontres avec l'écrit.

12 La bibliothèque de $\mathrm{CE}$ rencontre, alors, un problème : comment essayer de faire entrer le livre et la lecture à l'intérieur de cultures, historiquement, non ou peu livresques ? - voilà toute la question!

13 Pour appréhender les cultures non livresques, il lui faut :

- Comprendre l'originalité des lectures ouvrières afin de percevoir les techniques de lecture de ces faibles lecteurs. Retrouver le contexte culturel de ces pratiques de lecture, prises dans un réseau de relation avec d'autres pratiques du lecteur. Cerner la manière dont la lecture s'insère à l'intérieur des modes de vie (Bahloul, 1987 ; Naffrechoux, 1987 ; Peroni, 1988).

- Comprendre les pratiques culturelles des milieux populaires afin de percevoir les possibilités livresques à l'intérieur de ces espaces d'expression. Partir de ce qui fait sens dans la culture populaire (Robine, 1984).

\section{L'originalité des pratiques de lectures ouvrières}

14 Les ouvriers lisent peu. Mais ils lisent néanmoins. Partons de ces pratiques réelles pour percevoir les spécificités des lectures en milieux ouvriers.

15 Ces lectures sont soit des lectures qui accompagnent les activités prioritaires, soit des lectures-détente (Verret, 1988).

\section{La lecture comme pratique d'accompagnement}

\section{Accompagnement des loisirs privilégiés}

16 La lecture est ici une pratique productive qui apporte quelque chose. Une pratique utile. L'écrit joue un rôle d'explication. Technique et pratique, il accompagne des activités de loisirs prioritaires dans le mode de vie ouvrier.

17 La lecture a une fonction de "soutien » des activités de loisirs. C'est une lecture au coup par coup, sur le moment. Elle a une faible autonomie par rapport aux centres d'intérêts qui fondent le mode de vie ouvrier.

18 Les thèmes de lecture sont fortement différenciés sexuellement: bricolage dans la maison, entretien de la voiture, sport, jardinage, camping, caravaning, électronique, informatique pour les hommes.

19 Tricot, gestion du foyer, éducation des enfants, diététique médecine pour les femmes. Préparation des vacances pour les hommes et les femmes.

\section{Accompagnement de l'écoute de la télévision}

Télévision et lecture sont ici complémentaires. Plusieurs résultats d'enquêtes indiquent qu'en milieux ouvriers, la lecture (lecture des magazines présentant les programmes de 
télévision entre autres; les revues les plus lues par les milieux ouvriers sont les revues télé : Télé 7 jours, Télé poche, Télé star...) est fonction directe de l'écoute de la télévision. Toutes deux relèvent d'un même type de curiosité vis-à-vis de l'actualité (Choquet, 1990 ; Establet \& Felouzis, 1992 ; Verret, 1988).

\section{Accompagnement de la scolarité des enfants}

Les livres scolaires des enfants sont, dans beaucoup de familles ouvrières, les livres les plus présents. L'école apporte chaque année de nouveaux livres de classe à l'intérieur de l'espace familial et de nombreux parents suivent, quotidiennement, les efforts scolaires de leurs enfants (en « regardant » ces livres) (Naffrechoux, 1987).

\section{La lecture comme lecture-détente}

La lecture est ici attachée aux moments de fatigue. De solitude. Aux moments les plus faibles de la culture. Lorsqu'on est trop fatigué pour bricoler, faire du sport, etc. Lorsqu'on n'a plus rien à faire.

Cette lecture peut être effectuée durant le temps de travail. Un braconnage (une forme de «perruque »). Une pratique effectuée plus ou moins en cachette, pour tuer le temps, échapper à l'ennui des temps morts (de Certeau, 1980).

Lecture de revues, de journaux ou de romans policiers (San Antonio, SAS).

Lecture d'accompagnement, lecture-détente, les pratiques ouvrières de lecture privilégient certaines formes de présentation et d'écriture (Verret, 1988 ; Jauss, 1973) : les journaux et les revues sont plus appréciés que les livres. Ces lectures structurent de manière originale les consommations ouvrières de documents écrits :

- Les séquences de lecture sont courtes et sélectives.

- On accorde une place importante au temps présent, à l'actualité.

- On accorde une faible importance à l'auteur du texte lu.

- L'alphabet phonétique, les images et les idéogrammes tendent à se mélanger.

Il est important aussi de souligner qu'en milieu ouvrier les pratiques culturelles (hommes et femmes, jeunes et vieux) sont particulièrement contrastées.

27 À l'intérieur des activités des milieux populaires, les différences selon le sexe et l'âge sont très marquées. Les femmes privilégient la lecture des magazines féminins ou familiaux; les hommes, les matchs sportifs, les fêtes foraines, les bals publics ou la lecture d'un quotidien. Les loisirs des jeunes, extérieurs à la maison (matchs, fêtes, bals) s'opposent à ceux des personnes âgées, centrés sur le foyer (télévision, magazine, quotidien).

Les femmes qui ont des valeurs plus intérieures (plus tournées vers la vie familiale), qui écrivent plus souvent que les hommes, sont plus lectrices de romans (psychologiques) que les hommes (plus tournés vers l'utilité technique de la lecture).

\section{L'originalité des temps forts des cultures ouvrières}

Il est nécessaire de partir de ce qui fait sens dans les cultures populaires afin de mieux observer les possibilités livresques à l'intérieur de ces espaces originaux d'expression. 

n'est pas aux classes populaires, ce que la lecture est aux classes "cultivées", une manière active de mettre en marche l'imaginaire et du même coup de s'isoler.» (p.54) (c'est nous qui soulignons).

Chaque univers culturel forme une "grille assimilatrice» dont nous devons avoir conscience lorsque nous abordons les problèmes de lecture en milieux populaires (Chartier, 1985).

\section{BIBLIOGRAPHIE}

BAHLOUL J. - Lectures précaires. Étude sociologique sur les faibles lecteurs, Paris, Bibliothèque publique d'information, Centre Georges Pompidou, 1987.

BAKHTINE M. - L'œuvre de François Rabelais et la culture populaire au Moyen-Âge et sous la Renaissance, Paris, Gallimard, 1970 (1 $1^{\text {re }}$ éd. Moscou, 1965).

Certeau M. de - L'invention du quotidien, t. l, Paris, 10/18, 1980. 
CHARTIER R., ed. - Pratiques de la lecture, Marseille, Rivages, 1985.

CHoquet O. - « Vingt ans de développement des loisirs », Les Données Sociales 1990, Paris, INSEE, 1990, p. 213-216.

Establet R. \& Felouzis G. - Livre et télévision, concurrence ou interaction ? Paris, Presses universitaires de France, 1992.

JAuss H. R. - Pour une esthétique de la réception, Paris, Gallimard, 1978.

Mounin G. - Poésie et société, Paris, Presses universitaires de France, 1968 (1 ${ }^{\text {re }}$ éd. Paris, 1962).

NAFFRECHOUX M. - Lire, enquête sur la pluralité des mondes de la lecture, Thèse de $3^{\mathrm{e}}$ cycle en sociologie, Université de Paris VIII, 1987, multigr.

NAFFRECHOUX M. - « Des lecteurs qui s'ignorent. Les formes populaires de la lecture ", Bulletin de la Bibliothèque de France, t. 32, 5, 1987.

PASSERON J.-C. - « Figures et contestations de la culture » in Id. Le raisonnement sociologique.

L'espace non-popperien du raisonnement naturel, Paris, Nathan, 1991, p. 291-334.

PASSERON J.-C. - « Le polymorphisme culturel de la lecture » in Id. Le raisonnement sociologique.

L'espace non-popperien du raisonnement naturel, Paris, Nathan, 1991, p. 335-346.

PERONI M. - Histoires de lire. Lecture et parcours bibliographique, Paris, Bibliothèque publique

d'information, Centre Georges Pompidou, 1988.

RoBINE, N. - Les jeunes travailleurs et la lecture, Paris, Documentation française, 1984.

SEIBEL B. - Pratiques de loisirs et modes de vie des cheminots. Le cas de la lecture, Rapport de recherche, août 1989, multigr.

SORIANO M. - Les contes de Perrault. Culture savante et traditions populaires, Paris, Gallimard, 1968.

VERRET M. - « Choses lues », in Id. La culture ouvrière, Saint-Sébastien, ACL-Crocus, 1988, p. 153-163.

\section{NOTES}

*. Ce texte est la forme retravaillée d'une intervention orale effectuée devant des bibliothécaires de la région marseillaise en juin 1992. 